\title{
The use of fluid mechanics to explore human swimming technique
}

\begin{tabular}{|c|c|c|}
\hline $\begin{array}{l}\text { The use of science to compare } \\
\text { swimming mechanisms used } \\
\text { by humans and fish may } \\
\text { shed light on ways in which } \\
\text { human performance can be } \\
\text { improved. This underpins the } \\
\text { research of Professor Hideki } \\
\text { Takagi at the University of } \\
\text { Tsukuba, Japan, whose work } \\
\text { includes the hydrodynamic } \\
\text { and biomechanic study } \\
\text { of swimming to explore } \\
\text { the impact of competing } \\
\text { forces on performance of } \\
\text { competitive and artistic } \\
\text { swimmers and water } \\
\text { polo players. }\end{array}$ & $\begin{array}{l}\text { he mechanisms involved in } \\
\text { swimming involve harnessing } \\
\text { the propulsive force of the stroke } \\
\text { whilst overcoming the resistive force } \\
\text { of the water and the drag created by } \\
\text { the swimmer themselves. Indeed, it is } \\
\text { important to understand the mechanism } \\
\text { of propulsive force generation to ensure } \\
\text { that the swimmer gets the maximum } \\
\text { travel out of every stroke. } \\
\text { The hydrodynamic study of swimming } \\
\text { carried out by Professor Hideki Takagi, } \\
\text { University of Tsukuba, Japan, helps } \\
\text { swimmers and coaches to understand } \\
\text { more about the mechanisms behind } \\
\text { the stroke, meaning that they can adjust } \\
\text { technique accordingly and encourage } \\
\text { high performance in aquatic sports. He } \\
\text { uses flow visualisation, which creates } \\
\text { a visual representation of the flow } \\
\text { patterns present, in order to qualitatively } \\
\text { or quantitively analyse the fluid dynamics } \\
\text { at play during the swimming process. } \\
\text { FRONT CRAWL: A ROBOTIC HAND } \\
\text { One aspect of Professor Takagi's } \\
\text { earlier work explored the hydrodynamic } \\
\text { forces which acted on a robotic arm }\end{array}$ & $\begin{array}{l}\text { when mimicking the crawl stroke. } \\
\text { A robotic hand and arm were } \\
\text { controlled by a computer to mimic a } \\
\text { human performing a stroke of crawl. } \\
\text { The researchers measured forces } \\
\text { acting directly on the hand as it moved } \\
\text { through the water, and also the pressure } \\
\text { distributions around it. Images of the } \\
\text { fluid flow patterns were obtained using } \\
2 \mathrm{D} \text { particle image velocity (PIV). PIV is } \\
\text { a method of flow visualisation which } \\
\text { involves seeding the fluid through which } \\
\text { the object is moving with small particles } \\
\text { which, on illumination of the fluid, } \\
\text { become visible. The motion of the visible } \\
\text { particles can then be used to calculate the } \\
\text { speed and direction, or the velocity, of the } \\
\text { flow field being studied. } \\
\text { The data from this study demonstrated } \\
\text { that there are two mechanisms which } \\
\text { generate unsteady forces during a crawl } \\
\text { stroke, the point tat which the hand } \\
\text { changes direction and the stage at which } \\
\text { the hand moves away from the body in a } \\
\text { circular motion. Whilst unsteady fluid flow } \\
\text { may sound counterintuitive for swimming } \\
\text { speed, it is important for enhancing } \\
\text { propulsion through a process called }\end{array}$ \\
\hline
\end{tabular}

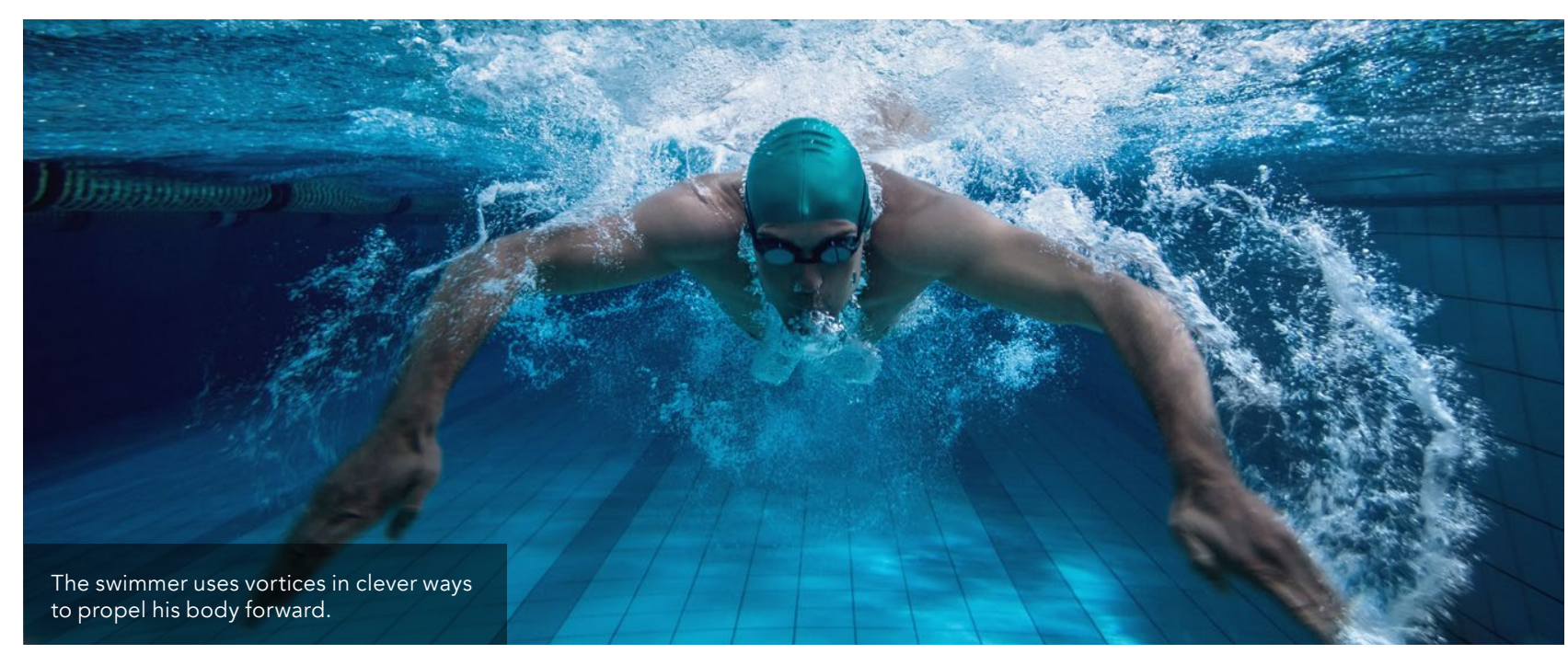

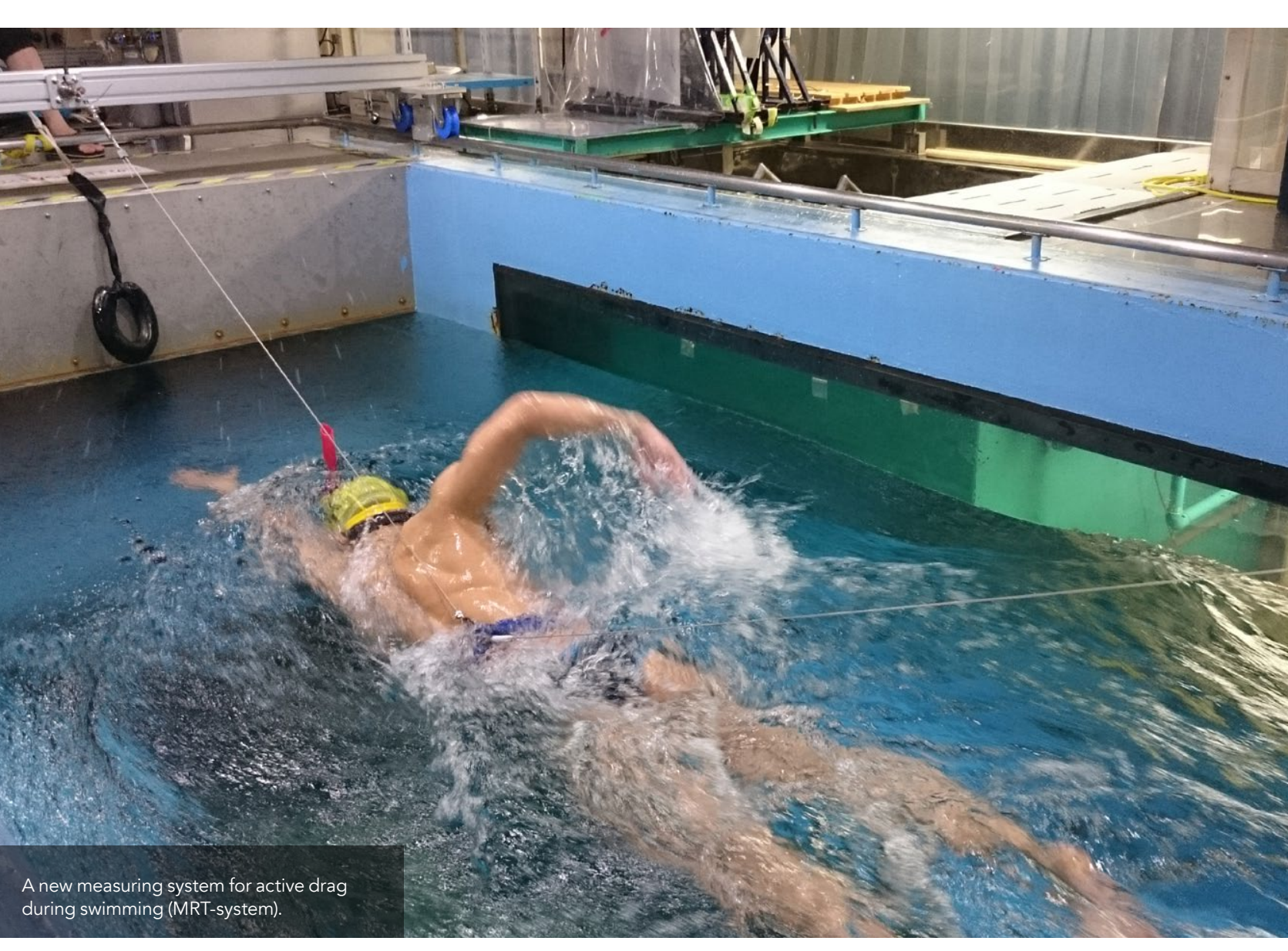

vortex recapturing, which harnesses two vortices of opposing directions.

a skilled swimmer is able to produce large unsteady forces, as with the craw Leading on from this work, now that stroke. These forces are created by the underlying mechanisms are better the outward movement of the edge understood, it would be beneficial to of the hand and the opposing inward investigate the flow fields using 3D PIV movement of the palm. Interestingly, and a human swimmer. the researchers also observed the same UNSTEADY FORCES ACT ON A HAND insects, suggesting that it is important for SCULLING

Further work undertaken by Professor vortices created during the swimming FLUID FORCES AROUND A FOOT DURING BREAST-STROKE It is not just the arm and hand that influence fluid forces during swimming the leg and foot also play a crucial role in producing propulsive force. When humans swim at a constant velocity, the average propulsive force is normally equal to the opposing active drag force. However, there forces in an experimental setting Whilst methods have been suggested

on the flow field 1 for estimating fluid $\begin{aligned} & \text { of the hand during The mechanisms involved in swimming } \\ & \text { a sculling motion, }\end{aligned}$ forces acting on
other parts of the rather than involve harnessing the propulsive force swimmer's body, during crawl

The team again used PIV to investigate forces of motion acting on the hand during the sculling motion. One participant was included, and he was asked to execute a sculling motion in controlled-flow water whilst remaining in a fred position for as long as possible. $3 \mathrm{D}$ motion analysis olve harnessing the propulsive force as mentioned of the stroke whilst overcoming the previously, the resistive force of the water and the drag lowerlimbs haved less created by the swimmer themselves. attention. Therefore.

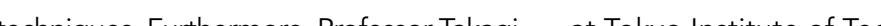
techniques. Furthermore, Professor Takagi sees potential for the findings from this study to be applied to synchronised swimming techniques and to help swimmers hold heir body position higher
in the water. at Tokyo Institute of Technology set out to test the use of a robotic leg to estimate fluid forces acting on the foot during kicking, and a human swimmer. 


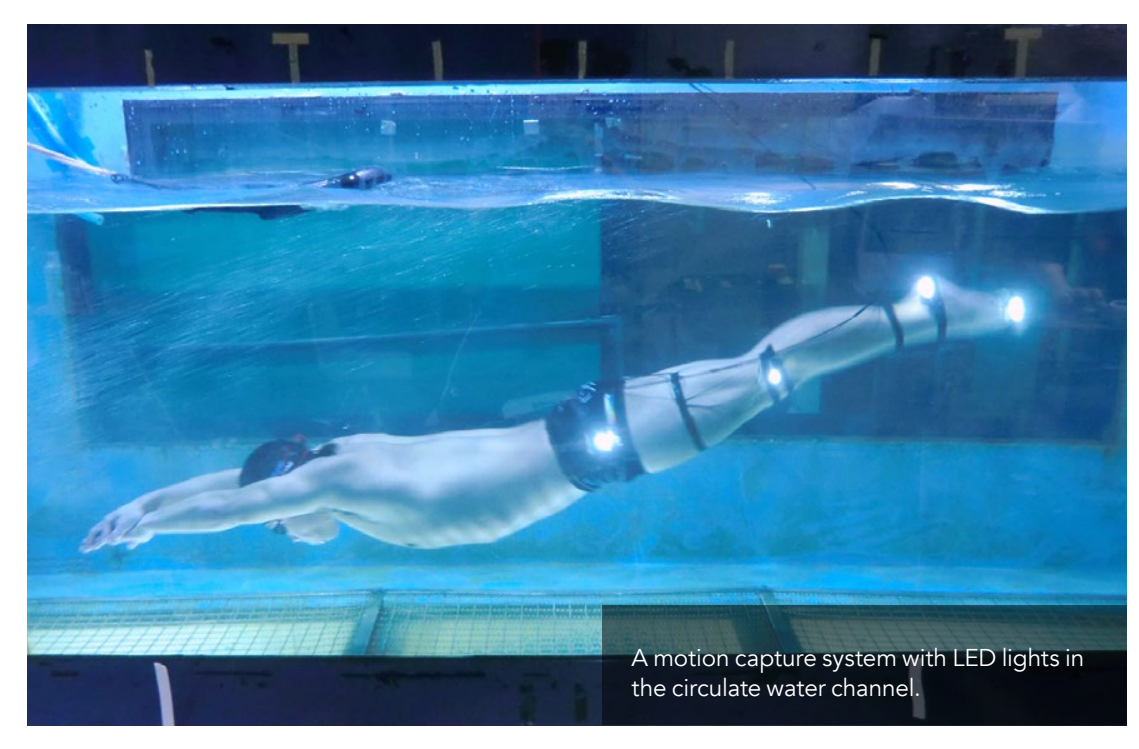

If propulsive forces generated by the swimmer can be harnessed more effectively, this will result in improved performance.

The trial showed that there was good correlation between the estimated fluid forced for the robotic leg and for the swimmer, suggesting that the robotic limb produced realistic results and may be therefore be useful for evaluating breast-stroke kicking motions and ultimately aiding a better understanding of kicking technique.

\section{THE EFFECT OF LEG KICK ON}

DRAG FORCE INFRONT-CRAWL

.

he brest-stroke leg kick and explor the effect of leg kick on active drag forces during front crawl. As the arms and legs move repeatedly across the water and create additional resistance from splash and waves, it is challenging to evaluate the resistance force acting on an active swimme.

Due to the complexity of the stroke, tis necessary to investigate the effect that kicking has on active drag by analysing swimmers with and without lower limb involvement.

In this trial, they compared the active drag produced from swimming with legs, the whole stroke. Active drag legs, the whole stroke. Active drag
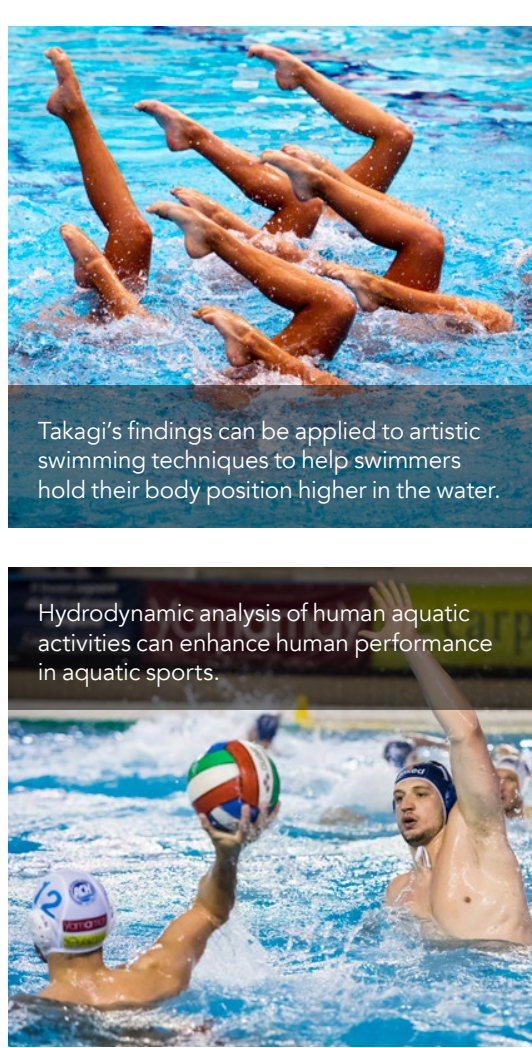

dolphin kick, which swimmers often use when pushing off from the edge of a pool after a turn.

A national level swimmer performed over 40 UUS trials. A motion capture system and PIV were used to capture the $3 \mathrm{D}$ flow fields around the swimme showing that the rotation of the lower limbs and the movement of the feet was responsible for producing vortices that Ultimuted in propulsion of the swimmer. Ultimately, the team were able to describe and explain the proplivis mechanism to examine the drag caused by leg motion during front-crawl and future active drag created when swimmers are exposed to recenditions. A limitation of the study is that each swimmer has a slightly different technique which ma influence results, but including other tools such as $3 \mathrm{D}$ motion analysis and pressure distribution analysis would. deepen understanding of the role of the leg kick during front-craw.

\section{THE 3D VISUALISATION OF FLOW} DURING THE DOLPHIN KICK In addition to breast-stroke and frontcrawl, the team at the University of Tsukuba have collaborated with researchers from Norway, Australia and other Japanese institutes to examine the propulsive mechanisms of undulato

CONCLUSION

\section{ค Behind the Research}

\section{Prof Hideki Takagi}

E: takagi.hideki.ga@u.tsukuba.ac.jp T: \pm 81-298536330 W: www.taiiku.tsukuba.ac.jp/ takagi/en/index.htm

\section{Research Objectives}

Professor Takagi's research is focused on the hydrodynamic analysis of the resistive- and propulsive-force in human aquatic activities, with a view to enhancing human

Detail

Professor Hideki Takagi

d Sport Sciences, University of Tsukuba, Tennodai 1-1-1, Tsukuba, Ibarak

3058574, Japan.

Professor Takagi received his B.E. degree in Physical Education from the University of Tsukuba, and his Ph.D. in Mechanical Engineering from Mie University. He then joined the Faculty of Health and Sports Sciences, University of Tsukuba, Japan, as an Assistant Professor, and full Professor in 2011. Professor Takagi is a fellow of the International Society of Biomechanics, and International Society of Sports Biomechanics, and life member of the Japanese Society of Sciences in swimming and water exercise. He was recipien the Komoto Awards, University of Tsukuba in 2004.

Funding

Japan Society for the Promotion of Science (JSPS).

Collaborators

Prof Makashima (Tokyo Institute of Technology) Dr Kazuo Matsuuchi (Emeritus Professor, University of Tsukuba)

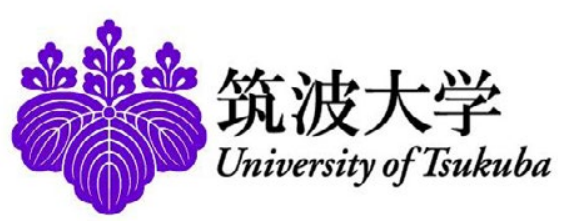

\section{References}

Shimojo, H., Gonjo, T., Sakakibara, J., Sengoku, Y., Sanders, R. \& Takagi, H. (2019). A quasi three-dimensional visualization of unsteady wake flow in human undulatory swimming, J.Biomech, https://doi.org/10.1016/j. jbiomech.2019.06.013

Narita, K., Nakashima, M. \& Takagi, H. (2018). Effect of leg kick on active drag on front-crawl swimming: Comparison of whole stroke and arms-only stroke during front-crawl and the biomech.2018.05.027

Tsunokawa, T., Nakashima, M. \& Takagi, H. (2015). Use of pressure distribution analysis to estimate fluid forces around a foot during breaststroke kicking. Sports Eng 18:149-156. https://doi.org/10.1080/02640414.2018. 1436189

Takagi, H., Shimada, S., Miwa, T., Kudo, S., Sanders, R. \& Matsuuchi, K. (2014). Unsteady hydrodynamic forces acting on a hand and its low field during sculling moton humov.2014.09.003

Takagi, H., Nakashima, M., Ozaki, T. \& Matsuuchi, K. (2014). Unsteady hydrodynamic forces acting on a robotic armand its flow field: Application to the craw stroke. J.Biomech, 47: 1401-1408. DOI: 10.1016/1. jbiomech.2014.01.046

\section{Personal Response}

You have already looked at the involvement of upper breast-stroke and front-crawl, but what will your future research focus on?

I Do you know why the 'free-style' event exists in competitive swimming even though $99.9 \%$ swimmers is the possibility using front-crawl? Because there is the possibility of inventing a new and even faster we would like to contribute to developing a new swimming style for swimmers and coaches through our research outcomes. 